\title{
Partially Turboelectric Aircraft Drive Key Performance Parameters
}

\author{
Ralph H. Jansen ${ }^{1}$ \\ NASA Glenn Research Center, Brook Park, Ohio, 44135 \\ Dr. Kirsten P. Duffy ${ }^{2}$ \\ University of Toledo, Brook Park, Ohio, 44135 \\ and \\ Dr. Gerald V. Brown ${ }^{3}$ \\ NASA Glenn Research Center, Brook Park, Ohio, 44135
}

The purpose of this paper is to propose electric drive specific power, electric drive efficiency, and electrical propulsion fraction as the key performance parameters for a partially turboelectric aircraft power system and to investigate their impact on the overall aircraft performance. Breguet range equations for a base conventional turbofan aircraft and a partially turboelectric aircraft are found. The benefits and costs that may result from the partially turboelectric system are enumerated. A breakeven analysis is conducted to find the minimum allowable electric drive specific power and efficiency, for a given electrical propulsion fraction, that can preserve the range, fuel weight, operating empty weight, and payload weight of the conventional aircraft. Current and future power system performance is compared to the required performance to determine the potential benefit.

\section{Nomenclature}

$D \quad=\operatorname{drag}$

$g \quad=$ gravitational constant

$h \quad=$ fuel energy per unit mass

$L \quad=$ lift

$P_{\text {elec }} \quad=$ electrical output power

$P_{\text {fuel }} \quad=$ fuel output power

$P_{\text {prop }} \quad=$ propulsive output power

$P_{\text {turbine }}=$ turbine output power

$R \quad=$ range of aircraft

$S p_{\text {elec }} \quad=$ specific power of electric drive system - key performance parameter

$T=$ total airplane thrust

$v_{\text {cruise }}=$ cruise

$W_{\text {initial }}=$ initial cruise weight of aircraft

$W_{\text {final }} \quad=$ final weight of aircraft

$W_{\text {elec }} \quad=$ electric drive weight

$W_{\text {fuel }} \quad=$ aircraft fuel weight

$W_{\text {pay }} \quad=$ payload weight

${ }^{1}$ Electrical Engineer, Aeronautics Mission Office, 21000 Brookpark Road, Brook Park, Ohio 44135, MS 162-3, and AIAA Member.

${ }^{2}$ Senior Research Associate, Mechanical, Industrial, and Manufacturing Engineering, 21000 Brookpark Road, Brook Park, Ohio 44135, MS 49-8, and AIAA Member.

${ }^{3}$ Senior Research Engineer, Structural Dynamics, Rotating and Drive Systems Branch, 21000 Brookpark Road, Brook Park, Ohio 44135 MS 49-8. 


$\begin{array}{ll}W_{\mathrm{OEW}} & =\text { empty weight of aircraft (operating empty weight) } \\ \gamma & =\text { constant relating electric drive power to partially turboelectric aircraft initial weight } \\ \zeta_{\mathrm{AC}} & =\text { fuel fraction of conventional turbofan aircraft } \\ \eta_{\text {elec }} & =\text { efficiency of electric drive system - key performance parameter } \\ \eta_{\text {prop }} & =\text { propulsive efficiency of aircraft } \\ \eta_{\text {therm }} & =\text { thermal efficiency of aircraft } \\ \xi & =\text { electrical propulsion fraction }- \text { key performance parameter }\end{array}$

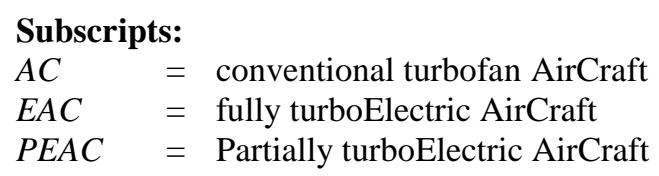

\section{Introduction}

$\mathrm{T}$ here is substantial interest in the investigation of improvements to aircraft efficiency through the introduction of electrical components into the propulsion system. In the case of a turboelectric aircraft, the electrical systems can provide unmatched flexibility in coupling the power generation turbine(s) to the fan propulsors. This flexibility can allow greater propulsion airframe integration and can result in reduced noise, emissions, and fuel burn. However, the greatly expanded electrical system introduces weight and efficiency burdens at odds with these benefits. A potentially promising intermediate step between a conventional turbofan aircraft and a fully turboelectric aircraft is a partially turboelectric propulsion system. Initial studies into partially turboelectric configurations show that a significant aerodynamic benefit can be achieved while only requiring a fraction of the propulsive power to be managed electrically. However, it is difficult to arrive at authoritative conclusions since the aircraft configurations themselves and many of the major electrical system components have yet to be built or verified. A breakeven analysis is presented here to elucidate the electrical power system performance requirements necessary to achieve a viable partially turboelectric aircraft. This first-order analysis provides a framework for comparing electric drive system performance factors, such as the electrical efficiency, in the context of aircraft propulsion systems. The value of this analysis is both to guide electrical system component research as well as to provide aircraft configuration researchers with reasonable component expectations.

A similar parametric analysis was presented previously for a fully turboelectric propulsion system. ${ }^{1}$ The current study focuses on a partially turboelectric propulsion system, where the fraction of thrust power will be varied between the turbofan engine(s) and electric distribution to additional propulsors. In order to conduct the breakeven analysis we first define the key performance parameters (KPPs), the key functional requirements, and the electrical power system boundary. Then we will formulate Breguet range equations for conventional turbofan and partially turboelectric aircraft. In this analysis we will assume that all of the thrust comes from various combinations of the turbofan engine and electrically driven fans where the electric power is generated at the turbine engine. Contributions from other power sources, such as batteries, are important considerations but outside the scope of this study. Next, the aerodynamic benefits that can be derived through new aircraft configurations are assigned as percentage improvements for the parametric considerations. Finally, we find the breakeven relationship by implicitly solving for the electric drive specific power and efficiency while holding constant the OEW, payload weight, fuel weight, and aircraft flight range. The resulting parametric curves can be used as the top-level requirements for the electrical power system and bounding guidelines for further aircraft exploration.

The breakeven assumptions in this analysis used to determine the values of the KPPs include

- The ranges of the conventional and partially turboelectric aircraft are equal.

- The initial fuel weights of the conventional and partially turboelectric aircraft are equal.

Other simplifying assumptions in this analysis include

- The payload weights of the conventional and partially turboelectric aircraft are equal.

- The OEW of the partially turboelectric aircraft is equal to the sum of the OEW of the conventional aircraft and the weight of the electrical drive system. 
- The electrical drive system includes the generator(s), rectifier(s), distribution wiring, fault protection, inverter(s), motor(s), and the thermal control for those components. Therefore, the electrical drive system efficiency and specific power are defined as including those components.

- The propulsive efficiency of the partially turboelectric system is assumed to be a single quantity, representing the turbofan(s) and motor-driven fan(s) in the aircraft, but including the gains in propulsive efficiency due to the partially turboelectric architecture (e.g., boundary layer ingestion (BLI) benefits).

- The electrical propulsion system provides the same power during the entire flight, but the power needs change during the flight. The electric propulsion fraction $\xi$ is defined based on cruise conditions. When $\xi=1$, this means that the cruise power is provided by the motor-driven fans only, but the conventional turbofans do provide power when required (e.g., during takeoff).

\section{Partially Turboelectric Propulsion System}

NASA is expanding its exploration of turboelectric drive propulsion options through a series of studies called Single-aisle Turboelectric AiRCraft (STARC). For example, a single-aisle commercial transport concept with a partially turboelectric propulsion system architecture was developed for notional entry into service (EIS) in 2035 and compared to a similar technology conventional configuration by Welstead and Felder. ${ }^{2}$ This concept, Single-aisle Turboelectric AiRCraft With Aft Boundary Layer

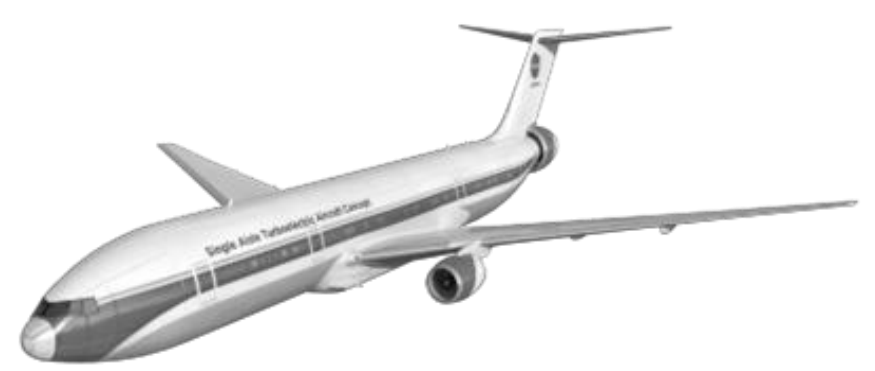

Figure 1. STARC-ABL concept. STARC-ABL, is shown in Fig. 1. The partially turboelectric architecture consists of two underwing turbofans with generators extracting power from the fan shaft and transmitting it to a rear fuselage, axisymmetric, boundary layer ingesting fan. Initial results indicate that the partial turboelectric concept has an economic mission fuel burn reduction of 7\%, and a design mission fuel burn reduction of $12 \%$ compared to the 2035 EIS conventional configuration. In this design the power to the tailcone fan is constant and contributes approximately $20 \%$ of the thrust at takeoff and about $45 \%$ of the thrust at cruise. An exploration of the design space was performed to better understand how the partially turboelectric architecture modifies the design space, and system studies were conducted to determine the sensitivity of thrust specific fuel consumption at top of climb and propulsion system weight to the motor power, fan pressure ratio, and electrical transmission efficiency of the aft boundary layer ingesting fan.

For the comparative analysis performed here, three types of propulsive systems and their respective key variables are defined. Turbofan, fully turboelectric, and partially turboelectric propulsion can be viewed as three ways to convert fuel energy to aircraft thrust. The conventional turbofan propulsion and partially turboelectric propulsion will be compared using the subsequent Breguet range and KPP analysis.

Figures 2 to 4 are simplified system diagrams of each type of system with key efficiencies and power variables identified. The conventional turbofan system is considered the baseline aircraft system for comparison. The building blocks of the systems are the fuel source, the turbine engine, the propulsor, and in the case of fully turboelectric and partially turboelectric propulsion, the electric drive. We denote the conventional turbofan aircraft, the fully turboelectric aircraft, and the partially turboelectric aircraft parameters with the subscripts AC, EAC, and PEAC, respectively.

The turbine, propulsor, and electric drive have associated thermal $\left(\eta_{\text {therm }}\right)$, propulsive $\left(\eta_{\text {prop }}\right)$, and electrical efficiencies $\left(\eta_{\text {elec }}\right)$. The fuel power $\left(P_{\text {fuel }}\right)$, turbine engine power $\left(P_{\text {turbine }}\right)$, electrical power $\left(P_{\text {elec }}\right)$, and propulsive power $\left(P_{\text {prop }}\right)$ are defined as output power of the fuel, turbine engine, electric drive, and propulsors, respectively. The variables in each of Figs. 2 to 4 illustrate the association between the propulsive subsystems, powers, and efficiencies for each propulsion system. In the partially electric case, we must introduce the electrical propulsion fraction $(\xi)$, which we define as the fraction of total aircraft thrust at cruise produced by electrically driven propulsors. When propulsion fraction $(\xi)$ is equal to one, all the thrust during cruise is provided by electrically driven propulsors. A fully turboelectric system is one in which all the thrust throughout the mission, including takeoff and cruise, is provided by electrically driven propulsors. As mentioned previously, the fully turboelectric case was covered by Jansen et al. in Ref. 1. 


\section{Electric Drive System}

Specific power $\left(S p_{\text {elec }}\right)$, efficiency $\left(\eta_{\text {elec }}\right)$, and the electrical propulsion fraction $(\xi)$ are proposed as the three KPPs of the electric drive system in a partially turboelectric aircraft. Specific power $S p_{\text {elec }}$ is the ratio of the rated output power to the mass of the system. Efficiency $\eta_{\text {elec }}$ is the ratio of the output power to the input power of the electric drive system. Electrical propulsion fraction $\xi$ is the fraction of total aircraft thrust at cruise produced by electrically driven propulsors. These three KPPs will be used to describe electrical power system performance and establish levels of performance necessary for greater efficiency than the base turbofan aircraft.

A wide electric drive configuration trade space exists for potential aircraft configurations. Even narrowed to turboelectric drive systems, power systems are differentiated by the power source, the distribution approach, the number of motor-driven propulsors, and the fraction of the total propulsive power that is provided electrically. The major electrical drive components considered here will be 1) one or more turbine(s), 2) the electrical generator(s), 3) the parallel, turbine-shaft-driven propulsor(s), 4) the motor-driven propulsor(s), 5) the power distribution system extending from the turbine engine to the motor-driven propulsors, and 6) the thermal management system. Moreover, the power distribution includes power electronics, electrical cables, and protection devices.

The boundary of the electric drive system is defined to lend meaning to the KPPs. For this paper, the boundary will include the electrical machines, the power management and distribution system, and the thermal system specifically related to heat removal in the two prior systems (Fig. 5). By this definition, a representative partially turboelectric system would include generator(s), rectifier(s), distribution wiring, fault protection, inverter(s), motor(s), and the thermal control for those components. Some variants of the electrical drive system may use a subset of these components or alternative layouts. The specific power and electrical efficiency analyzed in this study includes all of the components inside the boundary. Notably, the turbine engine and the propulsors are outside of the electric drive boundary.

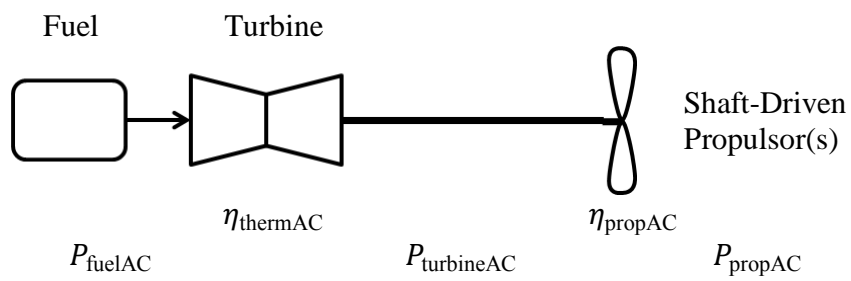

Figure 2. Conventional turbofan propulsion.

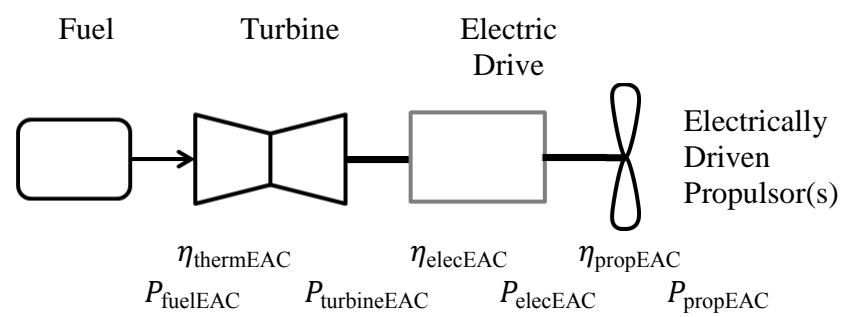

Figure 3. Turboelectric propulsion.

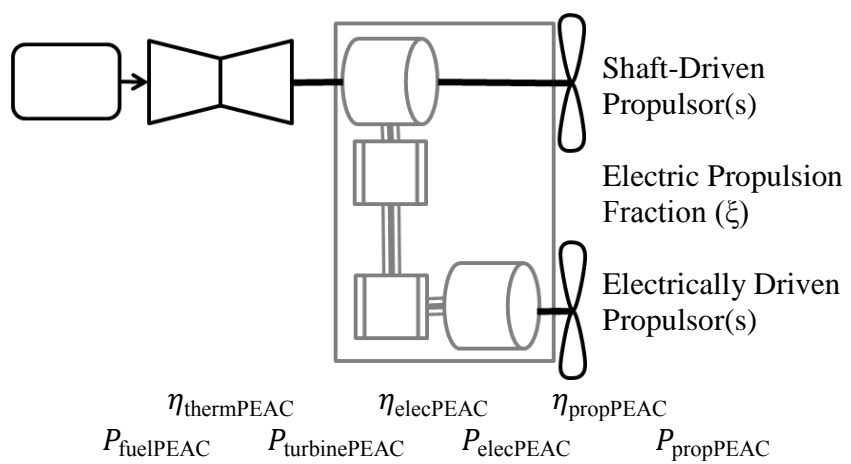

Figure 4. Partially turboelectric propulsion.

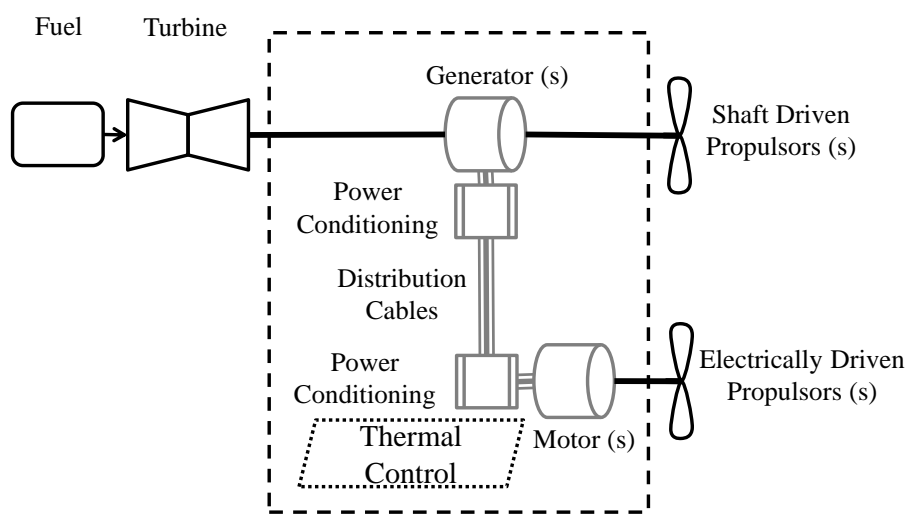

Figure 5. Electric drive system boundary.

\section{Aircraft Range}

A simplified assessment of the relationship between the electric drive system KPPs and the aircraft range is proposed for top-level aircraft performance comparisons. The basis of the analysis is an expansion of the traditional terms in the Breguet Range Equation shown in Eq. (1) to include the efficiency and weight of the turboelectric drive system. As such, it applies for situations where overall aerodynamic efficiency, the lift-to-drag (L/D) ratio, and flight 
velocity are constant over the flight. Although not true for the entire flight envelope, this description is a reasonable approximation for cruise conditions.

We develop Breguet range equations of the typical form representing the conventional aircraft and partially turboelectric configurations concurrently for comparison.

$$
R=\frac{h}{g} \frac{L}{D} \eta_{\text {overall }} \ln \left(\frac{W_{\text {initial }}}{W_{\text {final }}}\right)
$$

First, we quantify the portion of cruise thrust resulting from direct shaft-driven propulsors and electrically driven propulsors for the systems in Eq. (2).

Conventional Aircraft (a) Partially Turboelectric (b)

$$
T_{\mathrm{AC}}=T_{\text {shaft }} \quad T_{\text {PEAC }}=(1-\xi) T_{\text {shaft }}+\xi T_{\text {elec }}
$$

where $\xi$ is the electric propulsion fraction. Then, we expand the terms in the overall efficiency to include an electrical efficiency $\left(\eta_{\text {elec }}\right)$ in addition to the thermal and propulsive efficiency typically used:

$$
\begin{array}{cc}
\text { Conventional Aircraft (a) } & \text { Partially Turboelectric (b) } \\
\eta_{\text {overallAC }}=\eta_{\text {thermAC }} \cdot \eta_{\text {propAC }} & \eta_{\text {overallPEAC }} \\
& =(1-\xi) \eta_{\text {thermPEAC }} \cdot \eta_{\text {propPEAC }} \\
& +\xi \eta_{\text {thermPEAC }} \cdot \eta_{\text {elec }} \cdot \eta_{\text {propPEAC }}
\end{array}
$$

Next, we recognize the additional weight of the electrical drive impacts both the initial (Eq. (4)) and final weight (Eq. (5)) of the partially turboelectric aircraft, and expand each to explicitly account for the operating empty weight (OEW), payload, and fuel weight. Note that the payload weight is assumed to be the same in both aircraft types. We also assume that the OEW of the partially turboelectric aircraft is the sum of the OEW of the baseline conventional aircraft and the added electrical system weight, or $W_{\text {OEWPEAC }}=W_{\text {OEWAC }}+W_{\text {elecPEAC }}$. We also recall that the fuel weights are assumed to be equal for the breakeven analysis.

$$
\text { Conventional Aircraft (a) }
$$

$$
\begin{gathered}
W_{\text {initialAC }}=W_{\text {pay }}+W_{\text {OEWAC }}+W_{\text {fuel }} \\
W_{\text {finalAC }}=W_{\text {pay }}+W_{\text {OEWAC }}
\end{gathered}
$$

Partially Turboelectric (b)

$$
\begin{gathered}
W_{\text {initialPEAC }}=W_{\text {pay }}+W_{\text {OEWAC }}+W_{\text {elecPEAC }}+W_{\text {fuel }} \\
W_{\text {finalPEAC }}=W_{\text {pay }}+W_{\text {OEWAC }}+W_{\text {elecPEAC }}
\end{gathered}
$$

The range equation is now stated in Eq. (6) recognizing that in reality the partially turboelectric system can result in changes in the L/D ratio, thermal efficiency, propulsive efficiency, initial weight, and final weight of the aircraft. The partially turboelectric system shows promise when a large fraction of the benefits can be captured with a relatively small fraction of the thrust being delivered electrically.

$$
\begin{array}{cc}
\text { Conventional Aircraft (a) } & \text { Partially Turboelectric (b) } \\
R_{\mathrm{AC}}=\frac{h}{g}\left(\frac{L}{D}\right)_{\mathrm{AC}} \eta_{\text {overallAC }} \ln \left(\frac{W_{\text {initialAC }}}{W_{\text {finalAC }}}\right) & R_{\text {PEAC }}=\frac{h}{g}\left(\frac{L}{D}\right)_{\text {PEAC }} \eta_{\text {overallPEAC }} \ln \left(\frac{W_{\text {initialPEAC }}}{W_{\text {finalPEAC }}}\right)
\end{array}
$$

\section{Benefits From Turboelectric Aircraft Propulsion}

In this section, three proposed turboelectric aircraft propulsion-derived system benefits are described, and the potential fuel savings described in previous literature is summarized. Higher propulsive efficiency due to increased bypass ratio (BPR), higher propulsive efficiency due to BLI, and L/D ratio improvements are facilitated by turboelectric propulsion. Partially turboelectric solutions have the same potential benefits, but will not necessarily achieve the same level of each benefit. Although these benefits can also be achieved using alternate mechanical solutions, the introduction of electric coupling between the fan and turbine offers unmatched capability and design flexibility to achieve these aircraft system efficiencies. The actual improvements relative to an equivalent conventional aircraft will depend on detailed design decision. 
Introduction of an electric drive system between the turbine and fan allows decoupling of their speeds and inlet/outlet areas. With this approach, high BPR can be achieved since any number and size of fans can be driven from a single turbine. Increasing BPR results in improved propulsive efficiency. Also, the speed ratio between the turbine and the fan can be arbitrarily set and varied during operation, thereby removing a key constraint. As a result, the fan pressure ratio and the turbine/compressor ratios can be optimized independently. Studies with a hybrid-wing-body (HWB) distributed propulsion system indicate that the distributed propulsion system may optimize near a fan pressure ratio of 1.3 with resulting fuel savings around $4 \%$ to $8 \%{ }^{3,4}$ It is likely that thrust specific fuel consumption improvements will be somewhat less than propulsive efficiency improvements because of additional drag from larger fan duct areas; however, this varies by specific implementation.

BLI increases propulsive efficiency by ingesting lower velocity flow near the airframe into the propulsors, reenergizing the wake and thereby reducing drag. BLI can be implemented on both conventional tube-and-wing as well as HWB aircraft. The propulsor is mounted such that the slow moving flow near the aircraft is ingested, reenergized, and exhausted where the aircraft wake would have been. Plas et al. provided a review of many fuselage BLI studies; early estimates of aerodynamic efficiencies ranged from no improvements to $16 \%$ improvement and further refinement through the years resulted in estimations between 3\% and 7\%. ${ }^{5}$ More recently, MIT predicted the propulsive efficiency benefits of fuselage BLI on tube-and-wing style aircraft between $5 \%$ and $7 \%$, and verified them using reduced scale wind tunnel testing for the D8 aircraft concept. ${ }^{6}$ In a HWB configuration, the propulsors can be positioned for BLI on the top of the airframe, thereby reducing overall drag. A number of recent studies have examined the use of single-fan and multifan turbine engines embedded in the upper surface of a HWB aircraft. The predicted fuel burn reductions due to BLI in both configurations have been in the $3 \%$ to $8 \%$ range compared to a pylon mounted engine of equal technology level. ${ }^{4,7}$

Distributed propulsion is expected to improve both lift and L/D ratio through wing flow circulation control. The propulsors can be distributed above, below, or imbedded in the traditional tube and wing configuration. Likewise, HWB configurations can employ fans distributed across the upper surface or imbedded. Improvements in L/D ratio may result in smaller wing area, and reduced drag and weight. The benefits of lift augmentation can be taken in reduced wing area for a given load capacity or shorter takeoff distances. Reduction in wing area reduces wing weight, lowers drag, and thereby imparts fuel savings. Alternatively, the improved lift could be focused on increased climb rate and reduced takeoff distance in order to decrease the noise footprint around the airfield. One recent study by Wick et al. ${ }^{8}$ showed that transonic efficiency can be improved by as much as $8 \%$ for a transport-size aircraft. Stoll et al. ${ }^{9}$ evaluated the benefits of flow circulation control strategies using distributed propulsion on small aircraft and found that wing area could be reduced substantially. There are ongoing efforts to demonstrate the distributed propulsion benefits in small aircraft.

The ranges of benefits from the above paragraphs are summarized in Table 1, including the improved propulsive efficiency due to increased BPR and BLI, and the improved L/D ratio that can be expected for a large transport aircraft. Minimum, median, and maximum benefits are listed, and these ranges of possible benefits, scaled by electric propulsion fraction, will be used in this parametric evaluation.

Table 1. Range of Fully Turboelectric Benefits

\begin{tabular}{clll}
\hline & \multicolumn{2}{c}{$\eta_{\text {prop }}$ Improvements } & \multirow{2}{*}{ L/D } \\
\cline { 2 - 3 } & BPR & BLI & \\
\hline Minimum & $4 \%$ & $3 \%$ & $0 \%$ \\
Median & $6 \%$ & $5.5 \%$ & $4 \%$ \\
Maximum & $8 \%$ & $8 \%$ & $8 \%$ \\
\hline
\end{tabular}

\section{Costs of Electric Drive}

\section{A. Electric Drive Specific Power Impact}

The specific power is defined as a KPP because it has a direct impact on electric drive weight. The subsequent derivations are shown for the partially turboelectric system.

First, the thrust at the beginning of the cruise phase is found using the aircraft force balance:

$$
T=\frac{W_{\text {initial }}}{\left(\frac{L}{D}\right)}
$$

The following expressions for the electrical output power at the beginning of cruise are developed by recalling that the propulsive power is equal to the product of thrust and velocity. Additionally, the electrical power is found from the propulsive power requirement, the propulsive efficiency, and the electric propulsion fraction. For the partially turboelectric vehicle, the propulsive efficiency of the motor-driven fans and the turbofans is assumed to be the same; 
any efficiency benefits are assumed to be captured in Table 1 . The expression for the electric output power for the partially turboelectric aircraft during cruise is

$$
P_{\text {elecPEAC }}=\frac{\xi W_{\text {initialPEAC }} v_{\text {cruise }}}{\left(\frac{L}{D}\right)_{\text {PEAC }} \eta_{\text {propPEAC }}}=\gamma \xi W_{\text {initialPEAC }}
$$

where $\gamma$ relates the electric output power to the initial aircraft weight. We can find the electric drive system weight from the ratio of the electrical power and the specific power KPP, which is defined based on the cruise thrust requirement:

$$
W_{\text {elecPEAC }}=\frac{\xi W_{\text {initialPEAC }} v_{\text {cruise }}}{\left(\frac{L}{D}\right)_{\text {PEAC }} \eta_{\text {propPEAC }} S p_{\text {elec }}}=\frac{\gamma \xi W_{\text {initalPEAC }}}{S p_{\text {elec }}}
$$

\section{B. Fuel Weight Breakeven}

In this breakeven analysis, it is assumed that the initial fuel weights for the conventional aircraft and partially turboelectric aircraft are equal. We know the conventional aircraft initial fuel weight is the product of the fuel fraction $\zeta_{\mathrm{AC}}$ and the initial aircraft weight, or

$$
W_{\text {fuelAC }}=\zeta_{\mathrm{AC}} W_{\text {initialAC }}
$$

We can substitute Eq. (10) for fuel weight into Eq. (4a) to relate the fuel weight to the payload and OEW, which also happen to be the final weight of the conventional aircraft (Eq. (5a)):

$$
W_{\text {pay }}+W_{\text {OEWAC }}=W_{\text {finalAC }}=\left(1-\zeta_{\mathrm{AC}}\right) W_{\text {initialAC }}
$$

We can also define the fuel weight based on the partially turboelectric aircraft weights from Eq. (4b):

$$
W_{\text {fuelPEAC }}=W_{\text {initialPEAC }}-W_{\text {elecPEAC }}-W_{\text {pay }}-W_{\text {OEWAC }}
$$

Substituting Eq. (9) for $W_{\text {elecPEAC }}$ and Eq. (11) for $W_{\text {pay }}+W_{\text {OEWAC }}$ gives

$$
W_{\text {fuelPEAC }}=W_{\text {initialPEAC }}\left(1-\frac{\gamma \xi}{S p_{\text {elec }}}\right)-W_{\text {initialAC }}\left(1-\zeta_{A C}\right)
$$

We can set Eq. (10) and Eq. (13) for fuel weight equal to relate the initial weights of the two aircraft:

$$
W_{\text {initialAC }}=W_{\text {initialPEAC }}\left(1-\frac{\gamma \xi}{S p_{\text {elec }}}\right)
$$

The final weight of the partially turboelectric aircraft can be found by substituting Eq. (14), Eq. (11), and Eq. (9) into Eq. (5b):

$$
W_{\text {finalPEAC }}=W_{\text {initialPEAC }}\left(1-\zeta_{\mathrm{AC}}+\zeta_{\mathrm{AC}} \frac{\gamma \xi}{S p_{\text {elec }}}\right)
$$

\section{Range Breakeven Analysis}

The range breakeven analysis determines the electric drive specific power and efficiency for which the costs of adding the drive exactly equal the benefits achieved in terms of aircraft fuel weight for a specific mission range. This is a first-order analysis where the aircraft systems parameters are fixed to focus the evaluation on the aerodynamic and propulsive changes due to the introduction of the electric drive. Specifically, the OEW, payload weight, fuel weight, and mission range are all assumed to be constant. In many respects, these are conservative assumptions because once a propulsion airframe configuration is selected, additional optimization will be made.

First, the range expressions of the conventional aircraft and the partially turboelectric aircraft are equated: 


$$
\frac{h}{g}\left(\frac{L}{D}\right)_{\mathrm{AC}} \eta_{\text {overallAC }} \ln \left(\frac{W_{\text {initialAC }}}{W_{\text {finalAC }}}\right)=\frac{h}{g}\left(\frac{L}{D}\right)_{\text {PEAC }} \eta_{\text {overallPEAC }} \ln \left(\frac{W_{\text {initialPEAC }}}{W_{\text {finalPEAC }}}\right)
$$

Then the common terms are canceled and the efficiency terms from Eq. (3) substituted in

$$
\left(\frac{L}{D}\right)_{\mathrm{AC}} \eta_{\text {thermAC }} \eta_{\text {propAC }} \ln \left(\frac{W_{\text {initialAC }}}{W_{\text {finalAC }}}\right)=\left(\frac{L}{D}\right)_{\text {PEAC }} \eta_{\text {thermPEAC }} \eta_{\text {propPEAC }}\left[1-\xi\left(1-\eta_{\text {elec }}\right)\right] \ln \left(\frac{W_{\text {initialPEAC }}}{W_{\text {finalPEAC }}}\right)
$$

Next, the terms are arranged so the benefits are on the left and costs are on the right:

$$
\frac{\left(\frac{L}{D}\right)_{\mathrm{AC}}}{\left(\frac{L}{D}\right)_{\text {PEAC }}} \frac{\eta_{\text {thermAC }}}{\eta_{\text {thermPEAC }}} \frac{\eta_{\text {propAC }}}{\eta_{\text {propPEAC }}}=\left[1-\xi\left(1-\eta_{\text {elec }}\right)\right] \frac{\ln \left(\frac{W_{\text {initialPEAC }}}{W_{\text {finalPEAC }}}\right)}{\ln \left(\frac{W_{\text {initialAC }}}{W_{\text {finalAC }}}\right)}
$$

Finally, the initial and final weight relations from Eq. (11) and (15) are substituted into Eq. (18):

$$
\underbrace{\frac{\left(\frac{L}{D}\right)_{\mathrm{AC}}}{\left(\frac{L}{D}\right)_{\text {PEAC }}}}_{\begin{array}{c}
\text { aero } \\
\text { benefits }
\end{array}} \underbrace{\frac{\eta_{\text {thermAC }}}{\eta_{\text {thermPEAC }}} \frac{\eta_{\text {propAC }}}{\eta_{\text {propPEAC }}}}_{\text {propulsive benefits }}=\underbrace{\left[1-\xi\left(1-\eta_{\text {elec }}\right)\right]}_{\begin{array}{c}
\text { electrical } \\
\text { efficiency } \\
\text { cost }
\end{array}} \underbrace{\ln \left(\frac{1}{1-\zeta_{\mathrm{AC}}+\zeta_{\mathrm{AC}} \frac{\gamma \xi}{S p_{\text {elec }}}}\right)}_{\text {weight cost from specific power }}
$$

The aerodynamic and propulsive benefits discussed in this paper apply to the fully turboelectric aircraft. These values are assumed to scale with the electric propulsion fraction $\xi$ to obtain the benefits for the partially turboelectric aircraft. When we introduce $\xi$ into Eq. (19), we get the final breakeven equation for the partially turboelectric aircraft (Eq. (20)). Recall the subscript EAC refers to the fully turboelectric aircraft.

$$
\frac{1}{\xi} \frac{\left(\frac{L}{D}\right)_{\mathrm{AC}}}{\underbrace{\left.\frac{L}{D}\right)_{\text {EAC }}}_{\substack{\text { aero } \\
\text { benefits }}}} \underbrace{\frac{\eta_{\text {thermAC }}}{\eta_{\text {thermEAC }}} \frac{\eta_{\text {propAC }}}{\eta_{\text {propEAC }}}}_{\text {propulsive benefits }}=\underbrace{\left[1-\xi\left(1-\eta_{\text {elec }}\right)\right]}_{\begin{array}{c}
\text { electrical } \\
\text { efficiency } \\
\text { cost }
\end{array}} \underbrace{\ln \left(\frac{1}{1-\zeta_{\mathrm{AC}}+\zeta_{\mathrm{AC}} \frac{\gamma \xi}{S p_{\text {elec }}}}\right)}_{\text {weight cost from specific power }}
$$

Now we consider the form of Eq. (20). The benefits on the left are in terms of performance comparison ratios between the conventional baseline aircraft and the partially turboelectric aircraft. First, the aerodynamic changes are captured in the ratio of L/D performance, followed by the thermal and propulsive efficiency changes. The product of those ratios is the maximum total benefit. The right side has two main elements: the direct impact of electrical efficiency, and the electric drive system weight penalties that scale with specific power. Both expressions on the right side, as well as the expression on the left side, also are influenced by the electrical propulsion fraction.

Breakeven specific power and efficiency lines are now compared for the partially turboelectric aircraft cases using the minimum, median, and maximum expected BPR, BLI and L/D benefits. No change in thermal efficiency between the conventional and partially turboelectric aircraft is assumed. Table 2 lists the L/D and propulsive efficiency for each case for the fully turboelectric aircraft. The aircraft are assumed to have a velocity of $850 \mathrm{~km} / \mathrm{h}(\mathrm{Mach} 0.8)$, and the baseline conventional aircraft has a fuel fraction $\zeta_{\mathrm{AC}}$ of 0.15 .

The breakeven analysis is now done for electric propulsion fraction $\xi$ varying from $25 \%$ to $100 \%$. As one example of the breakeven analysis results, Fig. 6 shows the specific power and efficiency curve using the above aircraft parameters and the minimum, median, and maximum level benefit estimates for $\xi=100 \%$, where the electric drive provides all the power to the propulsors during cruise. For an assumed median benefit, Fig. 6 shows that the minimum required drive specific power must be $1.4 \mathrm{~kW} / \mathrm{kg}$ if the system was $100 \%$ efficient and the minimum required efficiency is $87 \%$ if the specific power was $20 \mathrm{~kW} / \mathrm{kg}$. If the electric drive system can be achieved with specific power 
and efficiency parameters that are in the region above the curve, the overall aircraft system will achieve a reduction in fuel weight, which could then be taken as payload or some alternate benefit. Not surprisingly, if the benefits are large, the KPPs of the power system do not need to be as aggressive. If the benefits are small, the KPP requirements become substantially more difficult. For example, the minimum required specific power is decreased from $3.4 \mathrm{~kW} / \mathrm{kg}$ in the minimum benefit case to $1.4 \mathrm{~kW} / \mathrm{kg}$ the median benefits case.

Figure 7 shows the breakeven curves for partial turboelectric power fractions of $75 \%, 50 \%$, and $25 \%$ for the median benefits case. Note that as the electric propulsion fraction $\xi$ decreases, the power system KPPs required for system benefits are eased, assuming the same benefit potentials. Figure 8 shows how these requirements change as the electric propulsion fraction increases for the median-level benefits case. The specific power at $100 \%$ efficiency decreases from $1.4 \mathrm{~kW} / \mathrm{kg}$ at $\xi=100 \%$ to $0.5 \mathrm{~kW} / \mathrm{kg}$ at $\xi=25 \%$. Similarly, at a specific power of $10 \mathrm{~kW} / \mathrm{kg}$, the required electrical efficiency decreases from $88 \%$ at $\xi=100 \%$ to $61 \%$ at $\xi=25 \%$.

Table 2. KPP Breakeven Cases

\begin{tabular}{lcc}
\hline & L/D & $\boldsymbol{\eta}_{\text {prop }}$ \\
\hline Conventional aircraft & 18.0 & 0.6 \\
$\begin{array}{l}\text { Minimum fully } \\
\text { turboelectric }\end{array}$ & 18.0 & 0.64 \\
$\begin{array}{l}\text { Median fully turboelectric } \\
\begin{array}{l}\text { Maximum fully } \\
\text { turboelectric }\end{array}\end{array}$ & 18.7 & 0.67 \\
\hline
\end{tabular}

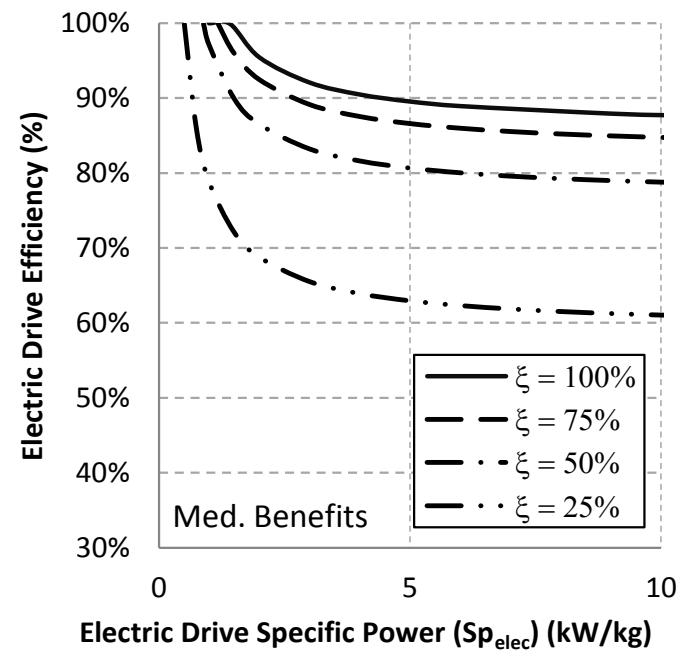

Figure 7. KPP breakeven curves for median benefits for varying $\xi$.

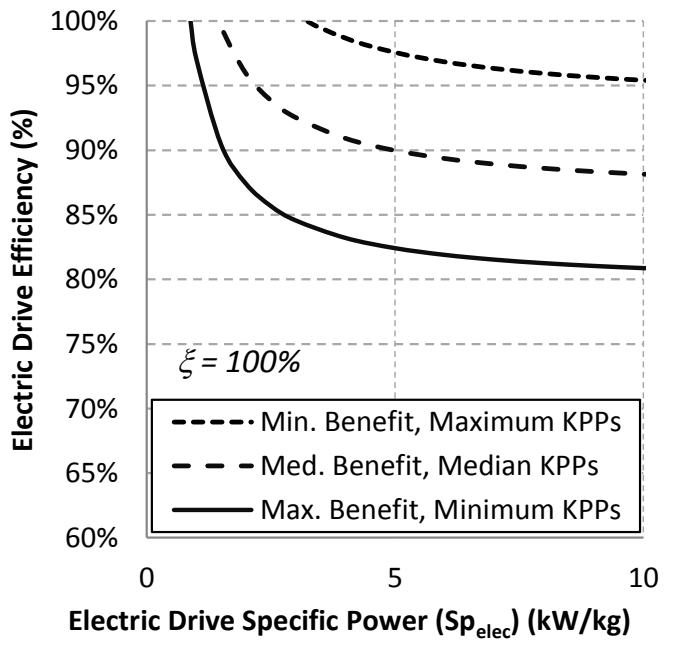

Figure 6. KPP breakeven curves for a range of benefits for $\xi=100 \%$ (all-electric power at cruise).

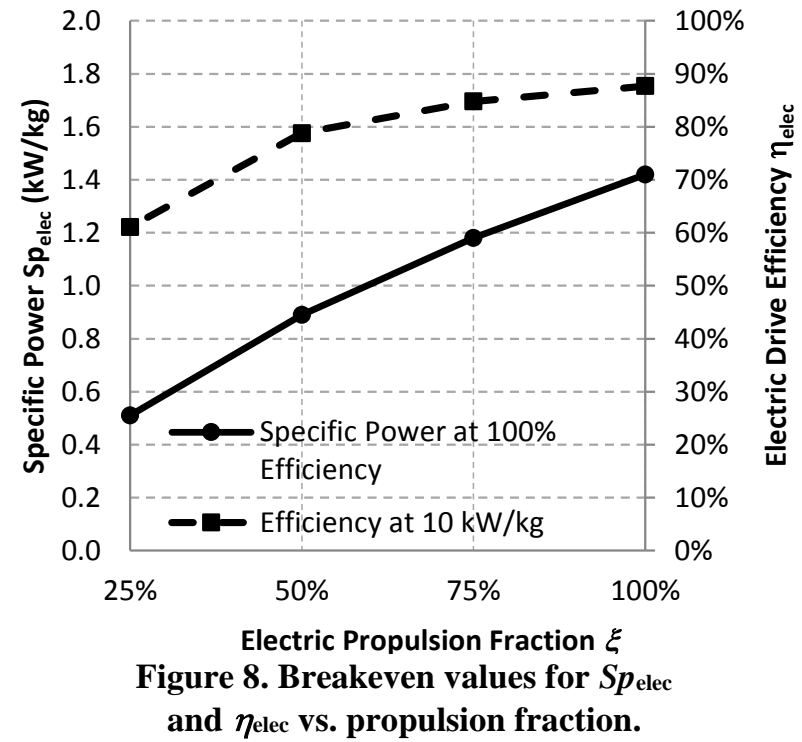




\section{STARC-ABL Example}

As a specific test case, the STARC-ABL concept aircraft is used to determine the breakeven values of electric drive specific power and electric drive efficiency. Table 3 shows the basic parameters for this aircraft as assumed or determined from Welstead and Felder. ${ }^{1}$ The propulsive efficiency is assumed to be the same for both the turbofan and tailcone thruster, a combined number, which is meant to include the BLI benefits of the tailcone thruster.

Figure 9 shows the breakeven analysis for this particular case. Since the fraction of propulsion derived turboelectrically is relatively low, $45 \%$ at cruise, the required electric drive efficiency and specific power are also relatively low to breakeven on weight and range. As can be seen in Fig. 9, the combination of KPPs for the STARC-ABL aircraft yields a design that is near the breakeven line. Welstead and Felder actually found that a total electrical efficiency of $90 \%$ with around $2 \mathrm{~kW} / \mathrm{kg}$ electrical specific power (including the thermal management system) yielded a reduction in fuel burn of $12 \%$. An important factor that may account for the difference between the two analyses is that the detailed analysis showed a decrease in weight of the turbofans, which essentially offset the increase from the electrical system, whereas an effect like that is not included in the relatively simple breakeven analysis.

\section{Conclusions}

The electrified aircraft propulsion options for commercial transport aircraft includes a very wide range of propulsion airframe integration options as well as electric drive train options. Bounding analyses or parametric trade studies can be very useful to help narrow choices for detailed studies as well as guide technology development choices. Specific power, efficiency, and electric propulsion fraction are proposed as key performance parameters (KPPs) for the electric drive system of a partially turboelectric aircraft. The boundary of the system is defined between the output shaft of the turbine to the input shaft of the propulsor and includes the electrical machines, power distribution, any other power components related to propulsion, as well as any thermal systems associated with the power system. The Breguet range equation was developed for the turboelectric aircraft and then combined with the Breguet range equation for the conventional baseline aircraft in order to develop an equation that compares the benefits and costs of a turboelectric system. The costs were associated with the proposed KPPs. Analysis of the performance costs leads to the conclusion that for a specific power below a certain level, which is dependent on both the electric power fraction and electrical efficiency, the specific power is the dominant cost, whereas above that level the efficiency becomes dominant. Essentially, there is a crossover point below which specific power is the key metric and above which electrical efficiency dominates. Finally, the KPP breakeven weight curves are found, which correspond to the minimum, median, and maximum estimated benefits resulting from the implementation of the partially turboelectric system. The region of power system performance that will result in a net weight benefit is shown. As one would expect, it is shown that the greater the combined aero and propulsive benefits are, the lower the specific power and efficiency of the turboelectric drive can be for the breakeven case.

\section{Acknowledgments}

This work is sponsored by the NASA Advanced Air Transportation Technologies project. The methods used in this paper build on an analytical approach developed by Gerald Brown for preliminary analysis of weights of electrical drive systems.

Table 3. STARC-ABL Parameters

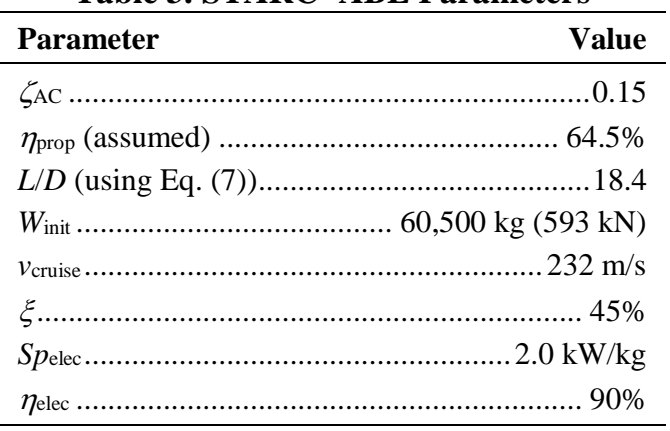

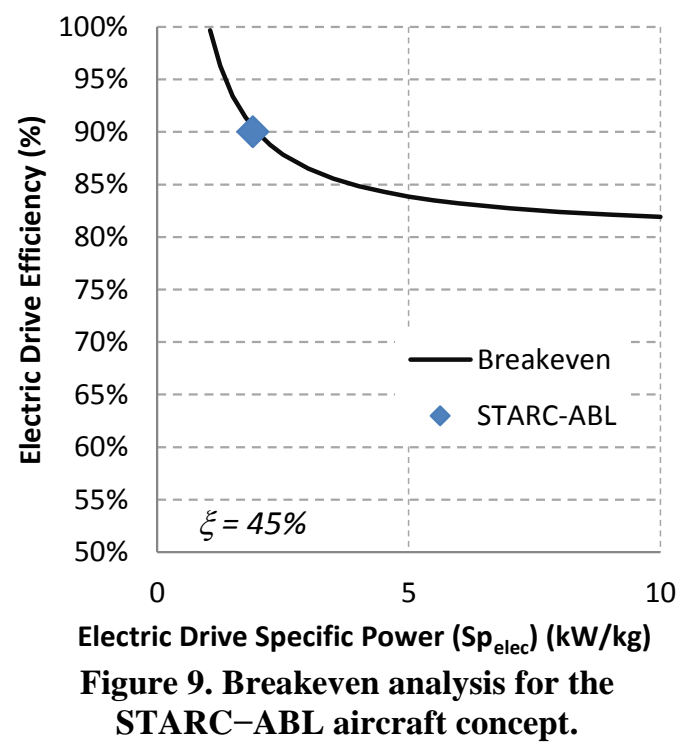




\section{References}

${ }^{1}$ Jansen, R. H., Brown, G. V., Felder, J. L., and Duffy, K. P., "Turboelectric Aircraft Drive Key Performance Parameters and Functional Requirements," 51 st AIAA/SAE/ASEE Joint Propulsion Conference, AIAA Propulsion and Energy Forum, AIAA 2015-3890, Reston, VA, 2015.

${ }^{2}$ Welstead, J. R., and Felder, J. L., "Conceptual Design of a Single-Aisle Turboelectric Commercial Transport with Fuselage Boundary Layer Ingestion," 54th AIAA Aerospace Sciences Meeting, AIAA SciTech Forum, AIAA 2016-1027, Reston, VA, 2016.

${ }^{3}$ Felder, J. L., Kim, H. D., and Brown, G. V., "Turboelectric Distributed Propulsion Engine Cycle Analysis for Hybrid-Wing-Body Aircraft," 47th AIAA Aerospace Sciences Meeting Including The New Horizons Forum and Aerospace Exposition, Aerospace Sciences Meetings, AIAA 2009-1132, Reston, VA, 2009.

${ }^{4}$ Brown, G. V., "Weights and Efficiencies of Electric Components of a Turboelectric Aircraft Propulsion System," 49th AIAA Aerospace Sciences Meeting including the New Horizons Forum and Aerospace Exposition, Aerospace Sciences Meetings, AIAA 2011-225, Reston, VA, 2011.

${ }^{5}$ Plas, A. P., et al., "Performance of a Boundary Layer Ingesting (BLI) Propulsion System," 45th AIAA Aerospace Sciences Meeting and Exhibit, Aerospace Sciences Meetings, AIAA 2007-450, Reston, VA, 2007.

${ }^{6}$ Uranga, A., et al., "Preliminary Experimental Assessment of the Boundary Layer Ingestion Benefit for the D8 Aircraft," 52nd Aerospace Sciences Meeting, AIAA SciTech Forum, AIAA 2014-0906, Reston, VA, 2014.

${ }^{7}$ Felder, J. L., Brown, G. V., Kim, H. D., and Chu, J., "Turboelectric Distributed Propulsion in a Hybrid Wing Body Aircraft," 20th International Society for Airbreathing Engines, ISABE-2011-1340, Gothenburg, Sweden, 2011.

${ }^{8}$ Wick, A. T., Hooker, J. R., and Zeune, C. H., "Integrated Aerodynamic Benefits of Distributed Propulsion," 53rd AIAA Aerospace Sciences Meeting, AIAA SciTech Forum, AIAA 2015-1500, Reston, VA, 2015.

${ }^{9}$ Stoll, A. M., Bevirt, J. B., Moore, M. D., Fredericks, W. J., and Borer, N. K., "Drag Reduction Through Distributed Electric Propulsion," 14th AIAA Aviation Technology, Integration, and Operations Conference, AIAA AVIATION Forum, AIAA 2014-2851, Reston, VA, 2014. 